\title{
Seasonal variations in length, dry weight, carbon and nitrogen of Calanus helgolandicus from the Celtic Sea
}

\author{
H. H. Bottrell and D. B. Robins \\ Natural Environment Research Council, Institute for Marine Environmental Research, Prospect Place, The Hoe, Plymouth, \\ Devon, PL1 3DH, United Kingdom
}

\begin{abstract}
Seasonal fluctuations in mean dry weight of the copepod Calanus helgolandicus were large and contrasted markedly with the small seasonal fluctuations of cephalothorax length. Dry weight was related linearly to cephalothorax length on logarithmic axes by a series of regression equations which were significantly different for each of 8 cruises. Carbon and nitrogen were likewise linearly related to dry weight on logarithmic axes and followed the seasonal fluctuations in dry weight. Dry weight and cephalothorax length showed little or no correlation with food concentration, ingestion rate, population numbers, population biomass or temperature. However, seasonal changes in dry weight could be explained in terms of Vidal's (1980a, b: Mar. Biol. 56: 111-134; 135-146) laboratory studies which relate growth rate and development time to body size, food concentration and temperature.
\end{abstract}

\section{INTRODUCTION}

There is an obvious need for reliable data on seasonal changes in dry weight, in order to minimize errors in calculating zooplankton biomass and production. Despite this, many of the published data for dry weights of marine copepods, including over 50 species, refer to temporally isolated samples (e.g. Orr, 1934; Nakai, 1955; Omori, 1969; Ikedan, 1974; Durbin and Durbin, 1978). Studies of the dry weight over an annual cycle have been made only for Calanus finmarchicus sensu lato (Bagorov, 1934; Marshall et al., 1934; Orr, 1934; Comita et al., 1966), Euchaeta norvegica (Båmstedt and Matthews, 1975; Bratellid and Matthews, 1978), Chiridius armatus (Båmstedt, 1978; Bakke and Alvarez Valderhaug, 1978), and Centropages typicus and Temora stylifera (Razouls, 1973). Since the taxonomic separation of Calanus finmarchicus s.l. (e.g. Rees, 1949; Jaschnov, 1955; Brodsky, 1959; Matthews, 1967) there has been only one seasonal survey of body size of Calanus helgolandicus (Claus) (Gatten et al., 1979); this dealt primarily with total lipid and lipid classes, and reported equations relating dry weight, carbon and nitrogen to total lipid for copepodite stage
$V$, male and female C. helgolandicus from the English Channel, but did not report seasonal changes in dry weight.

The studies made on Calanus finmarchicus s.l. provided evidence that temperature and food are the main factors affecting body size but, as with studies on the other copepods, did not propose a mechanism to explain the seasonal fluctuations. Vidal (1980a, b) gave details of laboratory investigations of the body size, growth rates and development times in relation to food concentration and temperature for the closely related species $C$. pacificus Brodsky. Vidal's studies will be used here to propose a possible mechanism to explain seasonal variations in body size of $C$. helgolandicus from the Celtic Sea.

In this paper Calanus is referred to by the species name used by the author cited in order to avoid confusion arising from taxonomic changes. In particular, it is probable that the species investigated by Bogorov (1934) off Plymouth was C. helgolandicus (Claus), and that the species referred to as $C$. helgolandicus (authority unspecified) by Mullin and Brooks (1970) and Paffenhöfer $(1971,1976)$ and as C. pacificus Brodsky by Frost (1972) and Vidal (1980a, b) are the 
same species (i.e. C. pacificus). C. helgolandicus (Claus) and $C$. pacificus Brodsky are considered independent but closely related species (Brodsky, 1975).

\section{MATERIALS AND METHODS}

Zooplankton was collected from around a central station $\left(51^{\circ} 30^{\prime} \mathrm{N} \quad 5^{\circ} 30^{\prime} \mathrm{W}\right)$ situated within a $14.8 \times 18.5 \mathrm{~km}$ sampling grid in the Celtic Sea on 8 cruises during February, March, May, June, August and October 1978, and January and March 1979. Samples were taken using a half-metre net of $280 \mu \mathrm{m}$ mesh, fitted with a detachable $500 \mathrm{ml}$ cod-end, deployed between a depth of $100 \mathrm{~m}$ and the surface. Immediately after collection the contents of the cod-end were distributed on to pieces of nylon mesh. After removal of the gelatinous zooplankton, the organisms remaining on the galize were rinsed in deionised water, covered with a thin polythene film and placed in a freezer.

On return to the laboratory the samples were defrosted and copepods carefully removed from the gauze. Only undamaged Calanus helgolandicus (Claus) were identified to developmental stage and subsequently used for analysis. Cephalothorax length (distance from tip of rostrum to posterior edge of cephalothorax) was measured to within $25 \mu \mathrm{m}$ using an eye-piece graticule, after which each Calanus was transferred to a numbered aluminium planchet and dried to constant weight in an oven at $60^{\circ} \mathrm{C}$. The dried copepods were stored in desiccators until cool and then weighed individually on a Cahn 25 Electrobalance readable to $0.1 \mu \mathrm{g}$. Carbon and nitrogen determinations were made using a Carlo-Erba CHN analyser with cyclohexanone 2, 4-dinitrophenylhydrazone (carbon $51.79 \%$, nitrogen $20.14 \%$ ) as the standard. Carbon and nitrogen measurements were made on individual Calanus in most cases but mean values were determined for copepodite stages II and III, using between 2 and 10 individuals per sample. Individual values, rather than means, were used whenever possible for fitting regression lines.

Size distribution (PSD) and total volume (TPV) of the suspended particulate matter, as well as feeding rates of Calanus, were measured using a Coulter Counter TA II with Population Accessory. Measurements were made on particles between 1.59 and $128.0 \mu \mathrm{m}$ equivalent spherical diameter.

Zooplankton population data were obtained from oblique hauls with a Longhurst-Hardy Plankton Recorder (Longhurst and Williams, 1976). Details of these samples are given in Williams and Conway (1982). Biomass for each cruise was calculated by summation of the products of mean numbers of each stage and mean dry weight for each stage.

\section{RESULTS}

Between-cruise variability is shown in Fig. 1. Mean cephalothorax length was relatively constant within each copepodite stage during the 14 mo of the study. In contrast, seasonal fluctuations of mean dry weight were not the same for each copepodite stage. The early stages showed little between-cruise variation whereas stage $\mathrm{V}$ and adults showed very large fluctuations in mean dry weight.

The means and ranges of values of dry weight and cephalothorax length for individuals of each stage for each cruise are given in Tables 1 and 2 respectively. Dry weight showed considerable within-cruise variability, especially during March 1978 in copepodite stages II, III, IV and V. At other times the variability was lower but there was nearly always considerable overlap in the dry weights of successive stages. In

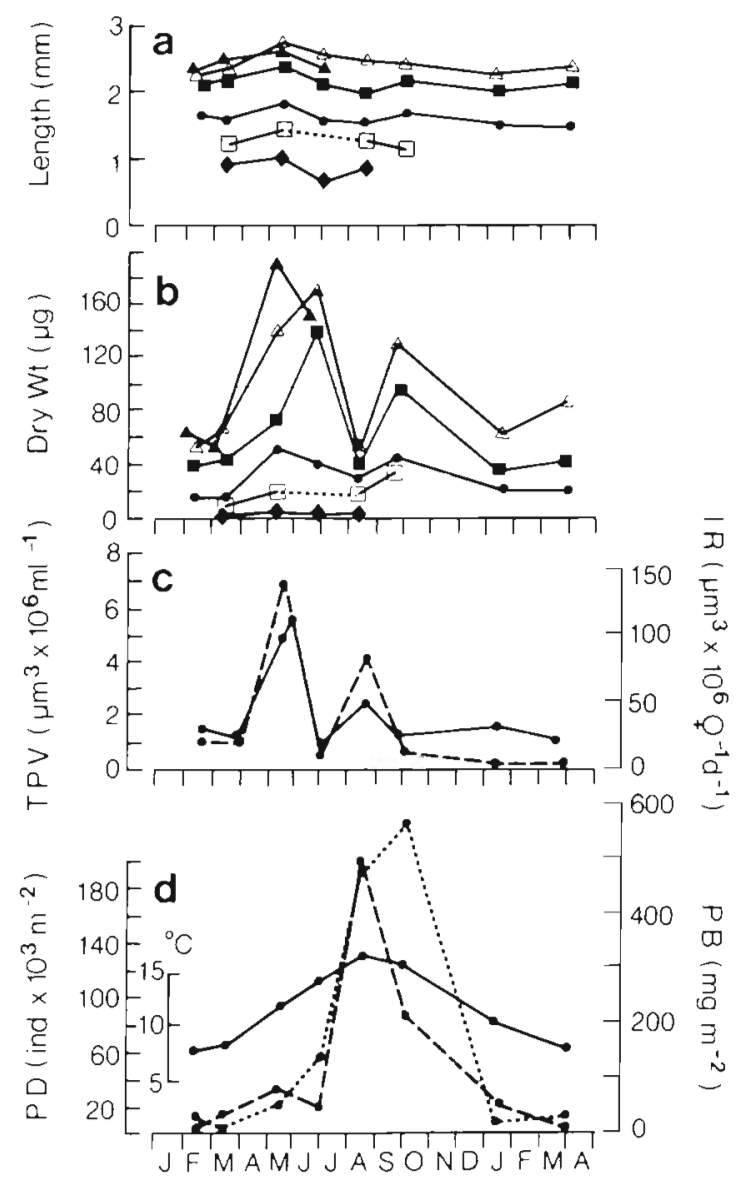

Fig. 1. Calanus helgolandicus. Seasonal variability. (a) Mean cephalothorax length for copepodite stages II $(\bullet)$, III (口), IV $(\bullet), V(\bullet), \quad,(\Delta), \delta(\Delta)$; (b) mean dry weight for the same copepods in relation to (c) total particulate volume (TPV, solid line) and ingestion rate of Calanus females (IR, dashed line), and (d) temperature $\left({ }^{\circ} \mathrm{C}\right.$, solid line), Calanus population density (PD, dashed line) and Calanus population biomass (PB, dotted line) 
Table 1. Calanus helgolandicus. Dry weight: (a) seasonal variations of mean ( \pm SE) in $\mu$ g; (b) range for each copepodite stage. Number in parentheses is the factor by which the maximum differs from minimum dry weight. Number of observations as in Table 2

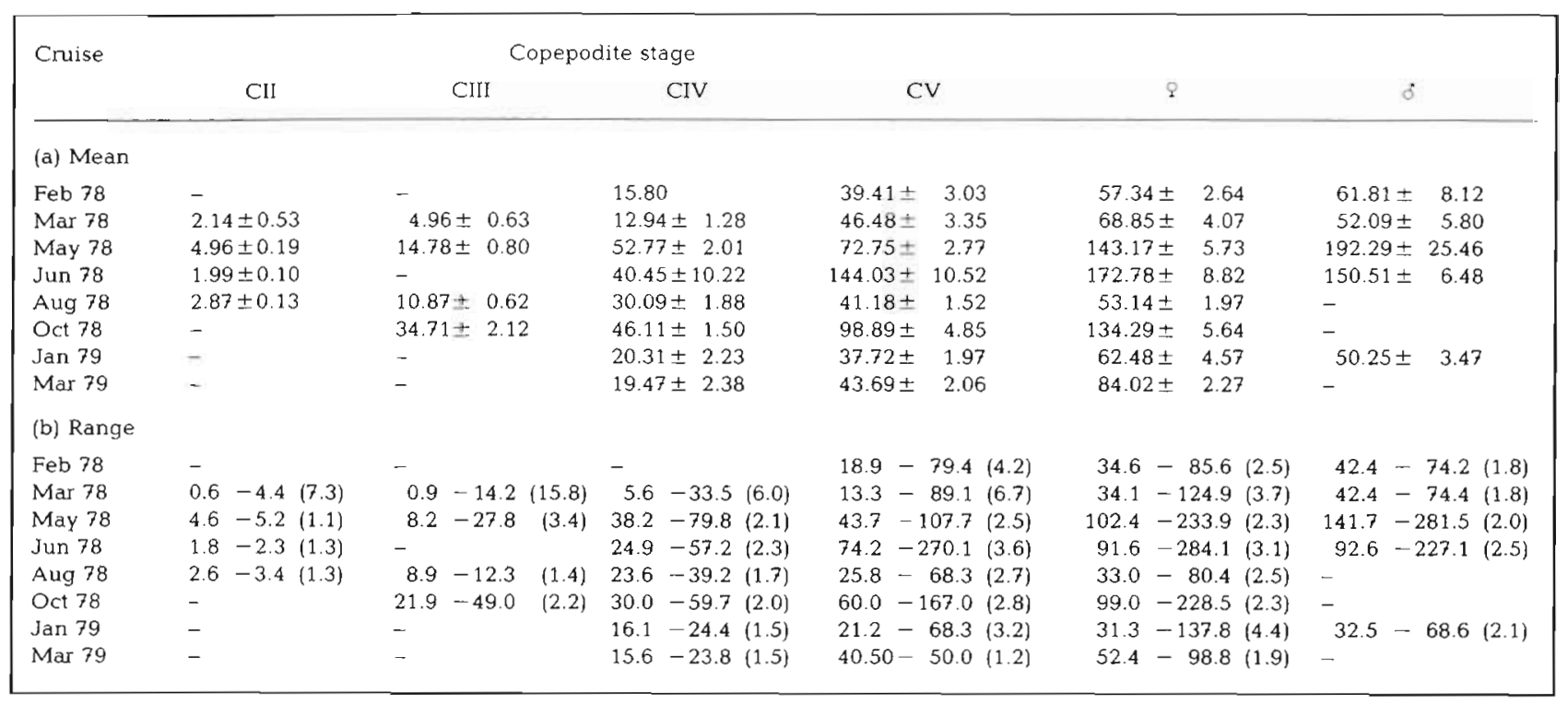

Table 2. Calanus helgolandicus. Cephalothorax length: (a) seasonal variations of mean ( $\pm \mathrm{SE}$ ) in $\mathrm{mm}$ with number of observations in parentheses; (b) range of length for each copepodite stage. Number in parentheses is the factor by which the maximum differs from the minimum length

\begin{tabular}{|c|c|c|c|c|c|c|}
\hline \multirow[t]{2}{*}{ Cruise } & \multicolumn{4}{|c|}{ Copepodite stage } & \multirow[b]{2}{*}{$\rho$} & \multirow[b]{2}{*}{$s$} \\
\hline & CII & CIII & CIV & $\mathrm{CV}$ & & \\
\hline \multicolumn{7}{|c|}{ (a) Mean } \\
\hline Feb 78 & - & - & $1.66-(1)$ & $1.99 \pm 0.03(30)$ & $2.25 \pm 0.02(30)$ & $2.26 \pm 0.02$ \\
\hline Mar 78 & $0.80 \pm 0.02(13)$ & $1.15 \pm 0.02(30)$ & $1.59 \pm 0.02(30)$ & $2.13 \pm 0.01(30)$ & $2.37 \pm 0.03(30)$ & $2.46 \pm 0.03$ \\
\hline May 78 & $0.99 \pm 0.04$ & $1.35 \pm 0.02(30)$ & $1.84 \pm 0.02(30)$ & $2.38 \pm 0.02(30)$ & $2.80 \pm 0.02(30)$ & $2.71 \pm 0.03$ \\
\hline Jun 78 & $0.51 \pm 0$ & - & $1.50 \pm 0.06(13)$ & $2.07 \pm 0.03(19)$ & $2.52 \pm 0.02(30)$ & $2.36 \pm 0.02(30)$ \\
\hline Aug 78 & $0.71 \pm 0.02$ & $1.22 \pm 0.02$ & $1.48 \pm 0.03(30)$ & $1.89 \pm 0.02(30)$ & $2.43 \pm 0.02(30)$ & - \\
\hline Oct 78 & - & $1.10 \pm 0.03(15)$ & $1.62 \pm 0.02(30)$ & $2.11 \pm 0.02(30)$ & $2.40 \pm 0.02(30)$ & - \\
\hline $\operatorname{Jan} 79$ & - & - & $1.47 \pm 0.04$ & $1.97 \pm 0.03(30)$ & $2.19 \pm 0.03(30)$ & $2.22 \pm 0.02(14)$ \\
\hline Mar 79 & - & - & $1.36 \pm 0.05$ & $2.09 \pm 0.07$ & $2.33 \pm 0.01(30)$ & - \\
\hline \multicolumn{7}{|c|}{ (b) Range } \\
\hline Feb 78 & - & - & - & $1.69-2.17(1.3)$ & $1.97-2.46(1.3)$ & $2.20-2.29(1.0)$ \\
\hline Mar 78 & $0.65-0.91(1.4)$ & $0.81-1.37(1.7)$ & $1.36-1.78(1.3)$ & $1.99-2.26(1.1)$ & $2.16-2.95\{2.4\}$ & $2.38-2.56(1.1)$ \\
\hline May 78 & $0.93-1.03(1.1)$ & $1.24-1.48(1.2)$ & $1.68-2.01(1.2)$ & $2.11-2.68(1.3)$ & $2.64-3.03(1.2)$ & $2.62-2.81(1.1)$ \\
\hline $\operatorname{Jun} 78$ & $0.51-\quad(0)$ & - & $1.38-1.57(1.2)$ & $1.78-2.40(1.4)$ & $2.40-2.85(1.2)$ & $2.16-2.56(1.2)$ \\
\hline Aug 78 & $0.66-0.76(1.2)$ & $1.12-1.29(1.2)$ & $1.37-1.64(1.2)$ & $1.66-2.10(1.3)$ & $2.32-2.61(1.1)$ & - \\
\hline Oct 78 & - $\quad$ h & $0.94-1.39(1.5)$ & $1.50-1.81(1.2)$ & $1.90-2.32(1.2)$ & $2.17-2.56(1.2)$ & - \\
\hline $\operatorname{Jan} 79$ & - & - & $1.37-1.51(1.1)$ & $1.81-2.26(1.3)$ & $1.99-2.43(1.2)$ & $2.11-2.38(1.1)$ \\
\hline Mar 79 & - & - & $1.29-1.45(1.1)$ & $1.93-2.26(1.2)$ & $2.33-2.44(1.1)$ & - \\
\hline
\end{tabular}

contrast, cephalothorax length showed much less within-cruise variability at all times of the year and there was little or no overlap between successive stages.

Although each stage did not attain its maximum dry weight at the same time, the general pattern of seasonal fluctuations in mean dry weight was similar for all stages, that is, high values in spring/early summer and autumn, and low values in August and winter (Fig. 1b). The slight evidence of a seasonal cycle of cephalothorax length suggested a similar pattern for all stages, the maxima for all stages occurring in May. This coincided with the dry weight maximum for males and for stage IV but preceded the maximum for females and for stage $\mathrm{V}$ by over 1 mo (Fig. 1).

The regressions relating the logarithm of dry weight to the logarithm of cephalothorax length for all individuals for each cruise are given in Table 3 . There was no evidence for different within-stage relationships for each cruise. A comparison of regressions showed sig- 
Table 3. Calanus helgolandicus. Linear regressions relating dry weight (DW) to cephalothorax length (CL). Regression equation: $\log _{e} D W=\log _{e} a+b \log _{e} C L$

\begin{tabular}{|c|c|c|c|c|c|c|}
\hline Cruise & $\log _{e} a$ & $b \pm S E$ & $\mathrm{df}$ & $F$ & $\mathrm{P}$ & $R^{2}(\%)$ \\
\hline Feb 78 & 1.8108 & $2.7383 \pm 0.4761$ & 1,63 & 33 & 0.001 & 34.2 \\
\hline Mar 78 & 1.2741 & $3.2340 \pm 0.1399$ & 1,136 & 535 & 0.001 & 79.7 \\
\hline May 78 & 1.8274 & $3.0708 \pm 0.0947$ & 1,127 & 1052 & 0.001 & 89.2 \\
\hline Jun 78 & 2.7346 & $2.7124 \pm 0.1069$ & 1,83 & 644 & 0.001 & 88.6 \\
\hline Aug 78 & 2.0691 & $2.2914 \pm 0.0994$ & 1,68 & 532 & 0.001 & 88.7 \\
\hline Oct 78 & 3.1313 & $1.9231 \pm 0.0872$ & 1,103 & 487 & 0.001 & 82.5 \\
\hline $\operatorname{Jan} 79$ & 1.6934 & $3.6668 \pm 0.4397$ & 1,72 & 70 & 0.001 & 49.1 \\
\hline Mar 79 & 2.0983 & $2.7136 \pm 0.2125$ & 1,35 & 163 & 0.001 & 82.3 \\
\hline
\end{tabular}

$\mathrm{SE}=$ standard error; $\mathrm{df}=$ degrees of freedom; $F=$ variance ratio; $\mathrm{P}=$ level of significance; $\mathrm{R}^{2}(\%)=\%$ of total variability explained by the regression

nificant differences between the equations for each cruise, i. e. regression equations calculated with a common intercept, a common slope or a common line gave a significant increase in the residual mean square in each case. Since dry weight is a power function of cephalothorax length, it is possible for small fluctuations in length to result in much larger fluctuations in weight. However, the effect of seasonal variations in cephalothorax length on dry weight can be removed by calculating mean dry weights adjusted to a standard length for each stage. A standardized cephalothorax length was calculated for each stage as the mean of all cephalothorax lengths for each stage from all cruises. This value was used in the regression equations in Table 3 to predict the adjusted mean dry weight for each standard length on each cruise (Fig. 2). The pattern of variation remains essentially the same as shown in Fig. $1 \mathrm{~b}$ and indicates that the large seasonal fluctuations in dry weight of stage $V$ and adults are not explicable by changes in cephalothorax length.

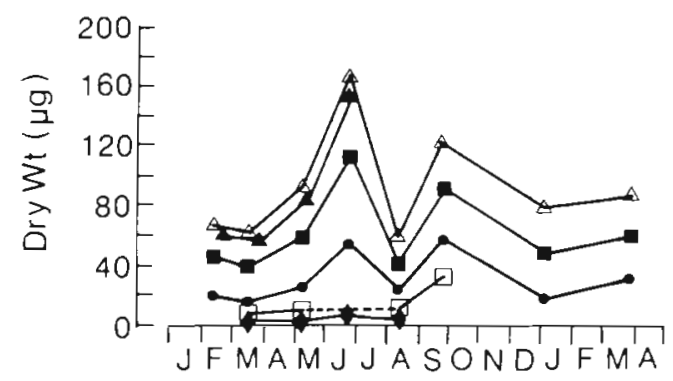

Fig. 2. Calanus helgolandicus. Seasonal variability of mean dry weight adjusted to a standardised cephalothorax length for copepodite stages II $(\bullet)$, III $(\square)$, IV $(\bullet), V(\bullet), P(\Delta), \delta(\Delta)$. Data are back-transformed from logarithmic values. See text for further details

On logarithmic axes there was a highly significant linear relationship between carbon per copepod and dry weight, and between nitrogen per copepod and dry weight, for all stages and all cruises (Fig. 3a, b). Thus

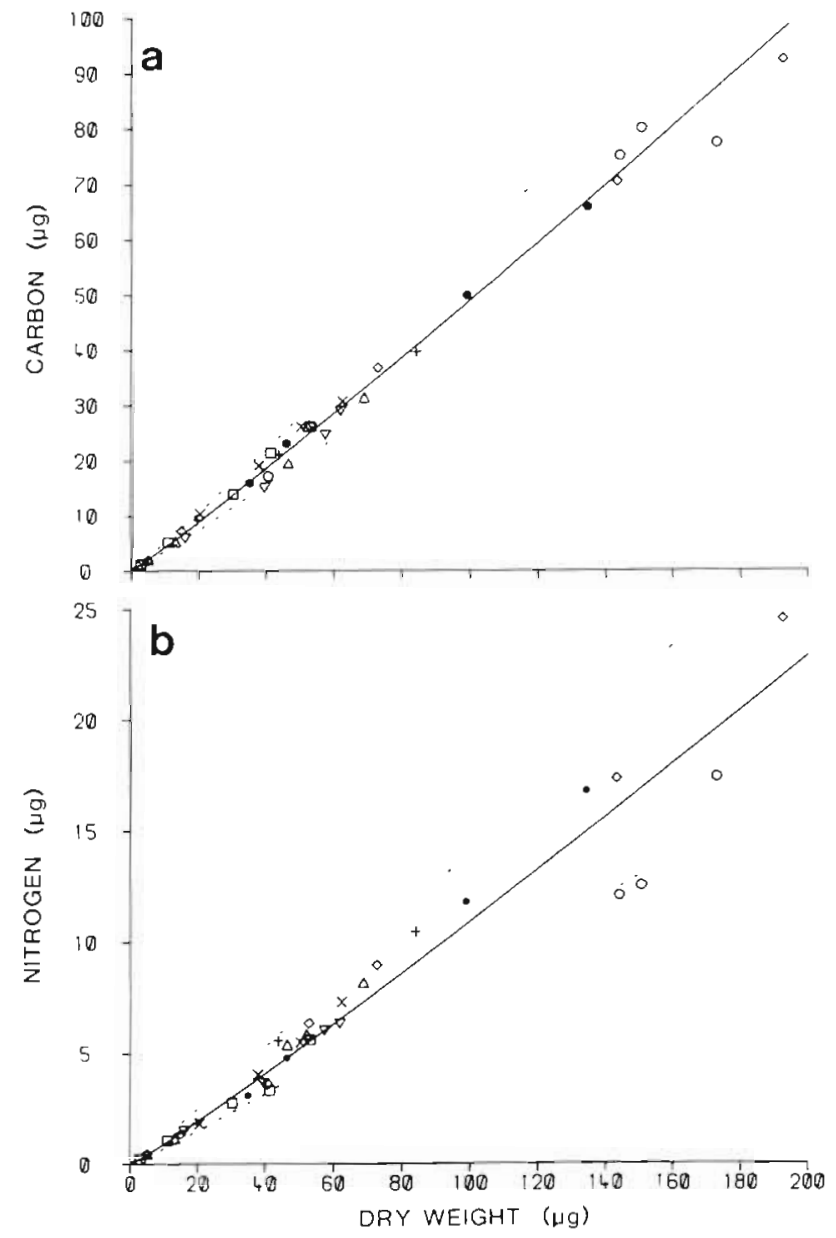

Fig. 3. Calanus helgolandicus. Relationship between dry weight and (a) carbon, (b) nitrogen for all copepodite stages on each cruise. Data are back-transformed from logarithmic axes and dotted lines show the $95 \%$ prediction limits on the data. Symbols distinguish cruise: 1978 - February $\nabla$, March $\triangle$, May $\diamond$, June 0 , August $\square$, October $\bullet, 1979$ - January $x$, March +. Regression equations ( \pm S.E.), with $n=36$ in both cases, are: $\log _{e} C=-0.9845( \pm 0.0491)+1.0593( \pm 0.0130)$ $\log _{e}$ DW and $\log _{e} N=-2.5341( \pm 0.0714)+1.0694( \pm 0.0189)$ $\log _{\mathrm{e}} \mathrm{DW}$ 
Table 4. Calanus helgolandicus. Seasonal variations of mean ( \pm SE) of (a) nitrogen and (b) carbon as a percentage of dry weight for each copepodite stage

\begin{tabular}{|c|c|c|c|c|c|c|}
\hline \multirow[t]{2}{*}{ Cruise } & \multicolumn{4}{|c|}{ Copepodite stage } & \multirow[b]{2}{*}{9} & \multirow[b]{2}{*}{8} \\
\hline & CII & CIII & CIV & $\mathrm{CV}$ & & \\
\hline \multicolumn{7}{|c|}{ (a) Nitrogen } \\
\hline Feb 78 & - & - & 9.92 & $9.52 \pm 0.67$ & $10.60 \pm 0.21$ & 10.34 \\
\hline Mar 78 & 8.18 & 7.82 & 8.41 & $11.41 \pm 1.54$ & $11.76 \pm 0.56$ & 10.97 \\
\hline May 78 & 9.68 & 9.29 & $12.08 \pm 0.30$ & $12.34 \pm 0.11$ & $12.13 \pm 0.28$ & 12.78 \\
\hline Jun 78 & - & - & 8.92 & $8.39 \pm 0.68$ & $10.17 \pm 0.24$ & $8.31 \pm 0.43$ \\
\hline Aug 78 & 8.93 & 9.94 & $9.17 \pm 0.33$ & $8.05 \pm 0.96$ & $10.52 \pm 0.58$ & - \\
\hline Oct 78 & - & 8.97 & $10.49 \pm 0.31$ & $11.95 \pm 0.29$ & $12.50 \pm 0.11$ & - \\
\hline $\operatorname{Jan} 79$ & - & - & 9.06 & $10.72 \pm 0.54$ & $11.68 \pm 0.23$ & $10.95 \pm 0.39$ \\
\hline Mar 79 & - & - & 9.50 & 12.71 & $12.44 \pm 0.11$ & - \\
\hline \multicolumn{7}{|c|}{ (b) Carbon } \\
\hline Feb 78 & - & - & 39.62 & $38.86 \pm 1.85$ & $43.43 \pm 0.91$ & 47.27 \\
\hline Mar 78 & 37.01 & 35.40 & $38.79 \pm 2.76$ & $41.27 \pm 2.78$ & $45.15 \pm 1.36$ & 49.60 \\
\hline May 78 & 38.71 & 49.27 & $49.90 \pm 0.46$ & $50.60 \pm 0.41$ & $49.38 \pm 0.74$ & 48.23 \\
\hline Jun 78 & - & - & 42.29 & $52.29 \pm 1.29$ & $44.93 \pm 2.26$ & $53.32 \pm 1.81$ \\
\hline Aug 78 & 44.23 & 47.88 & $46.27 \pm 1.29$ & $51.71 \pm 2.76$ & $49.06 \pm 0.38$ & - \\
\hline Oct 78 & - & 46.10 & $50.47 \pm 1.00$ & $50.40 \pm 0.41$ & $49.21 \pm 0.23$ & - \\
\hline Jan 79 & - & - & 51.32 & $50.47 \pm 1.79$ & $48.46 \pm 1.16$ & $51.92 \pm 0.98$ \\
\hline Mar 79 & - & - & 47.67 & 48.08 & $47.16 \pm 0.37$ & - \\
\hline
\end{tabular}

seasonal fluctuations in carbon and nitrogen are of the same magnitude and follow the same seasonal pattern as the fluctuations in dry weight shown in Fig. 1b. The values of the slope of the regression lines for carbon and for nitrogen are both significantly different from $\beta=1$ (carbon: $\mathrm{t}=4.57$ and nitrogen: $\mathrm{t}=3.68$, with 34 degrees of freedom $P<0.001$ in both cases). The slopes are slightly greater than unity (Fig. 3), indicating that carbon or nitrogen expressed as a percentage of dry weight increases only slightly as the dry weight increases. For example, from the regressions a $10 \mu \mathrm{g}$ copepod is predicted to contain approximately $11 \%$ nitrogen and $50 \%$ carbon. Observed values varied from 8.05 to $12.78 \%$ for nitrogen, and from 35.40 to $53.32 \%$ for carbon (Table 4 ).

It follows from the above results that seasonal variations in dry weight, carbon and nitrogen of Calanus helgolandicus from the Celtic Sea cannot be explained by variations in cephalothorax length.

Field measurements of total particulate volume, particle size distribution, temperature, ingestion rate of female Calanus, and the numerical abundance and biomass of the Calanus population were made on each cruise. The percentage of variability in cephalothorax length and in dry weight of copepodite stages IV and V and females explained by changes in some of these variables is given in Table 5 .

Total particulate volume (TPV) taken as a measure of food concentration, varied both spatially and temporally. There was no obvious relationship between copepod dry weight and TPV; the maximum of TPV
Table 5. Calanus helgolandicus. Percentage of variability $\left(\% \mathrm{R}^{2}\right)$ of cephalothorax length $(\mathrm{CL}, \mathrm{mm})$, dry weight (DW, $\left.\mu \mathrm{g}\right)$ and female ingestion rate ( $Q$ IR, $\mu \mathrm{m}^{3} \times 10^{6} \mathrm{Q}^{-1} \mathrm{~d}^{-1}$ ) explained by total particulate volume (TPV, $\mu \mathrm{m}^{3} \times 10^{6} \mathrm{ml}^{-1}$ ), Calanus numerical abundance (numbers, ind $\mathrm{m}^{-2}$ ), Calanus biomass $\left(\mathrm{mg} \mathrm{m}^{-2}\right)$ and temperature $\left({ }^{\circ} \mathrm{C}\right)$. Probability levels are given for the significant relationships only

\begin{tabular}{|c|c|c|c|}
\hline \multirow[t]{2}{*}{ Variables } & \multicolumn{2}{|c|}{ Stage } & \multirow[b]{2}{*}{$q$} \\
\hline & IV & V & \\
\hline CLv. TPV & 46 & 37 & $60^{\circ}$ \\
\hline CL v. Numbers & 8 & 16 & $<1$ \\
\hline CL v. Biomass & 3 & 4 & 3 \\
\hline CL v. Temperature & $<1$ & 2 & 13 \\
\hline DW v. TPV & 33 & $<1$ & 4 \\
\hline DW v. TPV (lagged) & 10 & $84^{\cdots}$ & $55^{\circ}$ \\
\hline DW v. Numbers & 6 & $<1$ & 3 \\
\hline DW v. Biomass & 13 & 8 & 19 \\
\hline DW v. Temperature & 47 & 28 & 17 \\
\hline Q IR v. TPV & - & - & $89^{\cdots} \cdot$ \\
\hline \multicolumn{4}{|c|}{$\cdot \mathrm{P}<0.05 ; \cdots \mathrm{P}<0.01 ; \cdots \mathrm{P}<0.001$} \\
\hline
\end{tabular}

occurred in May when dry weights of stage $V$ and females were increasing to their June maxima which coincided with the minimum mean TPV (Fig. 1b, c). Likewise, the August low in dry weights coincided with the dinoflagellate bloom, and the September peaks of dry weight occurred when TPV had dropped to $1.2 \mu \mathrm{m}^{3} \times 10^{6} \mathrm{ml}^{-1}(=\mathrm{ppm})$. The possibility of a lag effect between food concentration and dry weight was investigated. Lagging TPV by the sampling interval 
gave a significant correlation with dry weight of stage $\mathrm{V}$ and females but not for stage IV

The ingestion rate of females followed closely the food concentration curve (Fig. 1c); there was a highly significant correlation $(\mathrm{P}<0.001)$ between TPV and female ingestion rate (Table 5). Therefore, changes in ingestion rate do not provide a better explanation than TPV for seasonal changes in mean dry weight.

Calanus helgolandicus females in the Celtic Sea respond to seasonal changes in particle size distribution (PSD) by having a filtering rate curve (filtering efficiency) which varies to suit the PSD of the natural particulates on which they are feeding (unpubl.). It seems unlikely that seasonal changes in PSD would have a significant effect on seasonal changes in dry weight or cephalothorax length.

Seasonal fluctuations in temperature showed the sinusoidal curve typical of temperate latitudes with a maximum in August and low winter temperatures (Fig. 1d). There were no significant correlations between temperature and either dry weight or cephalothorax length (Table 5).

Seasonal fluctuations in numerical abundance and biomass of the Calanus population were similar except that biomass reached a maximum in October when numerical abundance was declining (Fig. 1d). This was due primarily to the marked increase in the dry weight of stage $V$ copepodites and females in October (Fig. 1b). No significant correlations were found between either cephalothorax length or dry weight and both measures of population size (Table 5).

\section{DISCUSSION}

In the present study between-stage variability in dry weight was explicable in terms of differences in cephalothorax length, using linear regressions whose parameters were significantly different for each cruise. The highly significant linear relationship between dry weight and carbon or nitrogen implies that for each cruise the between-stage changes in carbon and nitrogen are also explicable by differences in cephalothorax length. In contrast, between-cruise fluctuations in mean dry weight, carbon and nitrogen of each copepodite stage were not explicable in terms of any of the directly measured variables, i.e. cephalothorax length, food concentration, ingestion rate, temperature and Calanus population size. Although introducing a lag effect gave a significant correlation between food concentration (TPV) and dry weight of copepodite stage $\mathrm{V}$ and of females, published development times for Calanus do not support this as a convincing explanation. Development times for the closely related species C. finmarchicus and C. pacificus (Marshall and
Orr, 1955: Vidal, 1980b) suggest that $C$. helgolandicus will develop from copepodite stage $V$ to adult in approximately 4 to $14 \mathrm{~d}$ under the food and temperature conditions found in the Celtic Sea between June and September 1978. Therefore, it is most unlikely that Calanus would remain in the same copepodite stage over the 5 to 12 wk interval between cruises.

No attempt will be made to compare absolute values of dry weights and cephalothorax lengths from the present study with the earlier studies on Calanus finmarchicus s. I. (Marshall, 1933; Bogorov, 1934; Orr, 1934; Marshall et al., 1934; Comita et al., 1966). The methodology employed was often different, e.g. drying at $110^{\circ} \mathrm{C}$ and weighing groups of 100 Calanus in the earlier studies as against drying at $60^{\circ} \mathrm{C}$ and weighing individuals in the present study. The relatively recent taxonomic separation of Calanus finmarchicus s. l. further compounds the problems of comparison. However, it is possible to compare seasonal patterns of change and their relationship to environmental factors.

Comita et al., (1966) have summarized the earlier studies on seasonal changes in dry weight of Calanus finmarchicus s. 1. (see their Fig. 4). They noted that dry weights were usually lowest in February or March and that each study showed a sudden large increase in dry weight during March and April in Scottish waters (Marshall et al., 1934; Orr, 1934; Comita et al., 1966), or during April and May in the English Channel (Bogorov, 1934). This coincided with the spring diatom increase. The spring maximum of dry weight was usually attained in April or May, but in some years continued into June. After the maximum, which did not always coincide for all the stages, there was a rapid decrease in dry weight followed by a seasonal pattern which differed greatly from one study to another. In the English Channel the post-spring decrease was not large and there was a rise to secondary maximum in August followed by a decrease to minimum dry weights in October and December (Bogorov, 1934). In Loch Striven there was a continuous fall from June to September or October when observations ceased. On this fall was superimposed a series of fluctuations related to the production of each brood (Marshall et al., 1934). In Loch Fyne the dry weight of copepodite stage V C. finmarchicus continued to rise slightly from April to August and fell little until October (Orr, 1934). In the Bute Channel, dry weights decreased from the spring maximum to an August minimum but increased again during September and October to reach a maximum in December and January when dry weights were similar to those of the spring maximum (Comita et al, 1966).

The data from the Celtic Sea conform to this pattern of similarities between the winter and spring periods 
and dissimilarities for the rest of the year. There was a marked increase in dry weight during April and May, which did not coincide for all copepodite stages. The rest of the seasonal pattern consisted of a large decrease in August followed by a secondary maximum in September which declined to low winter levels. This latter part of the seasonal pattern is similar to that described for Calanus from the English Channel (Bogorov, 1934), differring only in the size of the decrease in June and August.

Orr (1934) offers no explanation for the seasonal fluctuations of dry weight in Loch Fyne while in the other studies only qualitative explanations are offerred. In the English Channel and Loch Striven it is suggested that low temperatures produce large copepods and that high temperatures produce small ones (Bogorov, 1934; Marshall et al., 1934). It is suggested also that the minor summer fluctuations in Loch Striven are related to diatom increases (Marshall et al., 1934). In the Bute Channel the weight changes were thought to be related to food fluctuations. Attempts to derive both qualitative explanations and quantitative relationships for the seasonal changes in the Celtic Sea data were likewise unsuccessful.

A seasonal survey of body size of Calanus helgolandicus (Gatten et al., 1979) showed dry weight to be correlated with total lipid and nitrogen for copepodite stage $\mathrm{V}$ and males, but only with nitrogen for females. The seasonal fluctuations of total lipid exhibited the same seasonal pattern as fluctuations in dry weight of Calanus from the English Channel (Bogorov, 1934) and from the Celtic Sea (Fig. 1b). Gatten et al. (1979) concluded that fluctuations in phytoplankton lipid did not explain the seasonal fluctuations of lipid in C. helgolandicus.

Deevey $(1960,1964)$ investigated the relative effects of temperature and phytoplankton concentration on the seasonal variations of cephalothorax length of marine copepods from various geographical areas. She found that in areas with an annual mean temperature range of $14{ }^{\circ} \mathrm{C}$ or more there was a significant negative correlation between cephalothorax length and temperature at the time of sampling. In areas with an annual mean temperature range of $14{ }^{\circ} \mathrm{C}$ or less there were significant positive correlations between cephalothorax length and mean phytoplankton concentration of the previous month. This implies that the phytoplankton is not limiting the cephalothorax length of marine copepods in areas of high annual temperature fluctuation. McLaren (1963) and Corkett and McLaren (1978) concluded, primarily from their work on Pseudocalanus, that food concentration has no effect on the final cephalothorax length of marine copepods. It is unfortunate that cephalothorax length was used as the dependent variable in these studies. The present study (Fig. 1a, b) and data from others (Bogorov, 1934; Marshall et al., 1934; Comita et al., 1966) have shown cephalothorax length, although a good indicator of developmental stage, to be a less sensitive measure of seasonal changes in body size than dry weight. Also the relationship between cephalothorax length and dry weight did not remain constant for Calanus from the Celtic Sea (Table 3).

Laboratory studies on Calanus helgolandicus (Mullin and Brooks, 1970; Paffenhöfer, 1971, 1976), C.pacificus (Frost, 1974), C. cristatus (Omori, 1970), and Temora longicornis (Harris and Paffenhöfer, 1976) have shown food concentration to affect body size measured as dry weight. However, none of these studies has defined the relationship. In a series of laboratory experiments Vidal (1980a, b) showed that food concentration, temperature and body size (dry weight) were fundamental in determining the growth rate and development times of Calanus pacificus.

The relationships defined by Vidal are summarized below and in Fig. 4a-f. He found that weight-specific growth rate (Fig. $4 \mathrm{a}, \mathrm{d}$ ) increased for all body weights with increasing food concentration up to a maximum level above which food concentration had no further effect, and that maximum growth rate decreased with increasing body weight. The critical food level at which maximum growth rate was attained increased with increasing temperature and body weight. In small copepodites the maximum growth rate decreased rapidly as temperature decreased (Fig. 4a) but became gradually less temperature dependent with increasing body size such that in copepodite stages $\mathrm{V}$ and VI maximum growth rate was virtually independent of temperature (Fig. 4d). He found also that development times (Fig. 4b, e) decreased to a minimum value with increasing food concentration and that the critical food concentration at which minimum development times were attained increased with increasing temperature and stage of development (and therefore body weight). Above the critical food level development times increased as temperature decreased. The development time-temperature relationship was such that low temperature retarded the development rate of early copepodites proportionally more than that of later copepodites. Development time increased with stage of development (and therefore body weight) at all temperatures and food concentrations.

The outcome of the complex of relationships and differential effects defined by Vidal (1980a, b) was that the early (small) copepodite stages, which develop faster than the later (large) copepodite stages, showed little variation in dry weight. The dry weight of stage II copepodites was found to be relatively unaffected by either food concentration or temperature (Fig. 4c). In contrast, the later copepodite stages showed much 

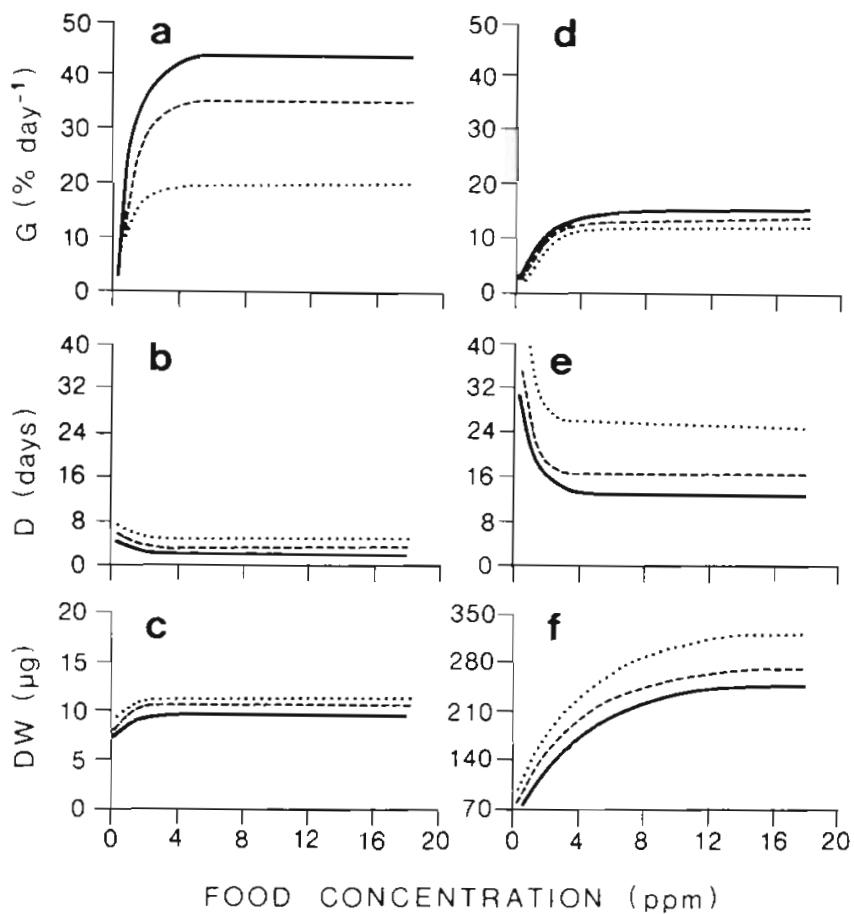

Fig. 4. Calanus pacificus. Relationships between food concentration and weight-specific growth rate (G), development time (D) and dry weight (DW) for copepodite stage II (a), (b), (c), and stage VI (d), (e), (f), cultured at $15.5^{\circ} \mathrm{C}$ (solid line), $12{ }^{\circ} \mathrm{C}$ (dashed line) and $8{ }^{\circ} \mathrm{C}$ (dotted line). (Redrawn from Vidal $1980 \mathrm{a}, \mathrm{b})$

greater variation in dry weight, and according to Vidal (1980a) were lightest at high temperatures and heaviest at low temperature for a given food concentration (Fig. 4f). The development times of stage $\mathrm{V}$ copepodites were longer at low temperatures than at high temperatures but their growth rates were similar at all temperatures. Clearly dry weight is a balance between growth rate and development times, the latter determining the length of time a particular growth rate is experienced. For example, in late copepodites a given growth rate over a long development time results in heavier individuals than the same growth rate over a shorter development time, whereas different growth rates (i.e. at different food concentrations below the critical level for growth) can produce late copepodites of similar dry weights for different development times. The pattern of little variation in the dry weights of the early copepodite stages and progressively more variation in the later copepodites is an agreement with the degree of variation observed in the copepodite stages in the Celtic Sea (Fig. 1b).

The ability of the two-way relationships defined by Vidal $(1980 \mathrm{a}, \mathrm{b})$ to predict the seasonal variations in dry weight of female Calanus helgolandicus from the Celtic Sea was examined. The data for stage V-VI given in Table 3 of Vidal (1980b) were used to produce a three-dimensional graph with dry weight as the dependent variable and stage duration and food concentration as the independent variables. Stage durations of C. helgolandicus were predicted from food and temperature conditions in the Celtic Sea, and their dry weights predicted from stage durations and food concentrations (Table 6). Agreement between the dry weights from the Celtic Sea and predictions based on Vidal's work are reasonably good between May and September 1978. The dramatic change in dry weights observed in August is particularly well accounted for, the temperature and food conditions giving high growth rates and very short development times which result in females of low dry weight. There are 2 possible explanations for the poor agreement between observed and predicted dry weights in the 4 winter months (February, March 1978 and January, March 1979). Firstly, although Vidal (1980a) states that there is always an inverse relationship between body size (dry weight) and temperature, his data (see Table 3 in Vidal, 1980b) do not always support this interpretation. At $8{ }^{\circ} \mathrm{C}$ (the lowest experimental temperature used by Vidal, 1980a, b) some of his observations have a dry weight lower than that observed at $12{ }^{\circ} \mathrm{C}$. Vidal (1980a) attributes this to clumping of the cells of Thalassiosira eccentrica at $8^{\circ} \mathrm{C}$ which resulted in retarded growth of Calanus pacificus. The second explanation for the dis-

Table 6. Calanus helgolandicus. Summary of seasonal fluctuations in dry weight of females, food concentration and temperature in the Celtic Sea with development times and dry weights predicted from Vidal $(1980 \mathrm{a}, \mathrm{b})$ for these food concentrations and temperatures

\begin{tabular}{|c|c|c|c|c|c|c|c|c|}
\hline & Feb & Mar & May & Jun & Aug & Sep & $\operatorname{Jan}$ & Mar \\
\hline Food concentration (ppm) & 1.4 & 1.1 & 5.2 & 1.0 & 2.5 & 1.2 & 1.6 & 1.2 \\
\hline Temperature $\left({ }^{\circ} \mathrm{C}\right)$ & 8 & 8 & 11.5 & 14 & 16.5 & 15.5 & 10 & 8 \\
\hline Stage duration (d) b & 12 & 15 & 6 & 10 & 4 & 7.5 & 10 & 14 \\
\hline \multirow{2}{*}{$\begin{array}{r}\text { o Dry weight }(\mu \mathrm{g}) \mathrm{a} \\
\mathrm{b}\end{array}$} & 57 & 69 & 143 & 173 & 53 & 134 & 63 & 84 \\
\hline & 115 & 120 & 150 & 120 & 55 & 105 & 105 & 120 \\
\hline
\end{tabular}


crepancy between observed and predicted dry weights is provided by the Celtic Sea data. Total particulate volume (TPV) may not always be the best expression of food concentration. The TPV for February/March 1978 and January/March 1979, although similar to the TPV for June and September, have a considerably lower organic content ( 12 to $18 \%$ as against 21 to $32 \%$ ), and hence lower food quality. The percentage organic content during the May and August bloom periods ranged from 26 to $40 \%$ and 20 to $70 \%$, respectively (unpubl.). If the values for food levels during the winter months are decreased relative to food levels in June and September, then using Vidal's (1980b) lowest food concentration, the predicted dry weights decrease to values between 70 and $85 \mu \mathrm{g}$. Since these winter food levels are below the critical concentration for growth, any further decrease in food concentration will further reduce dry weight.

Relationships derived for Calanus pacificus in the laboratory using diatom monocultures as food provide an acceptable explanation of the seasonal fluctuations in dry weight observed in the Celtic Sea for C. helgolandicus which had fed on natural particulates. The generality of the spring increase in dry weight is a result of overwintering Calanus of relatively poor somatic condition, due to low food and temperature, responding to marked spring increases in phytoplankton concentration and temperature. The dissimilarities in the rest of the seasonal pattern are a result of local variation in food and temperature conditions. A knowledge of the interactions between food concentration, temperature and body size and their differential effects on growth rates and development times as defined by Vidal (1980a, b) explains why previous studies were unable to provide convincing explanations for the seasonal fluctuations in dry weight.

Acknowledgements. The assistance of Mrs. G. J. Bailey, Mrs. M. D. Brinsley and Ms. S. C. Surey-Gent is gratefully acknowledged, as is the provision of Calanus population data by $\mathrm{Mr}$. R. Williams and advice on statistics by Dr. K. R. Clarke. We wish to thank the officers and crews of the NERC research vessels RRS John Murray and RRS Challenger, and our colleagues who participated in the cruises. This work forms part of the Coastal Ecology programme of the Institute for Marine Environmental Research which is a component Institute of the Natural Environment Research Council.

\section{LITERATURE CITED}

Bakke, J. L. W., Valderhaug, A. (1978). Ecological studies on the deep-water pelagic community of Korsfjorden, western Norway. Population biology, biomass and calorie content of Chiridius armatus (Crustacea, Copepoda). Sarsia 63: $247-254$

Bămstedt, U. (1978). Studies on the deep-water pelagic community of Korsfjorden, western Norway. Seasonal variations in weight and biochemical composition of Chiridius armatus (Copepoda), Boreomysis arctica (Mysidacea), and Eukrohnia hamata (Chaetognatha) in relation to their biology. Sarsia 63: 145-154

Båmstedt, U., Matthews, J. B. L. (1975). Studies of the deepwater pelagic community of Korsfjorden, western Norway. The weight and biochemical composition of Euchaeta norvegica Boeck in relation to its life cycle. In: Barnes, $\mathrm{H}$. (ed.) Proceedings of 9th European Marine Biology Symposium. University Press, Aberdeen, p. 311-327

Bogorov, B. G. (1934). Seasonal changes in biomass of Calanus finmarchicus in the Plymouth area. J. mar. biol. Ass. U. K. 19: 585-611

Bratellid, T. E., Matthews, J. B. L. (1978). Studies on the deepwater pelagic community of Korsfjorden, western Norway. The dry weight and calorific content of Euchaeta norvegica (Copepoda), Boreomysis arctica (Mysidacea) and Meganyctiphanes norvegica (Euphausiacea). Sarsia 63: 203-211

Brodsky, K. A. (1959). On phylogenetic relations of some Calanus (Copepoda) species of the northern and southern hemispheres. Zool. Zh. 38: 1537-1553

Brodsky, K. A. (1975). Phylogeny of the family Calanidae (Copepoda) on the basis of a comparative morphological analysis of its characters. In: Zvereva, Z. A. (ed.) Geographical and seasonal variability of marine plankton. Israel Program for Scientific Translations 1975, Jerusalem, p. $1-127$

Comita, G. W., Marshall, S. M., Orr, A. P. (1966). On the biology of Calanus finmarchicus. XIII. Seasonal changes in weight, calorific value and organic matter. J. mar. biol. Ass. U. K. 46: 1-17

Corkett, C. J., McLaren, I. A. (1978). The biology of Pseudocalanus. Adv. mar. Biol. 15: 1-123

Deevey, G. B. (1960). Relative effects of temperature and food on seasonal variations in length of marine copepods in some eastern American and western European waters. Bull. Bingham oceanogr. Coll. 17: 55-86

Deevey, G. B. (1964). Annual variations in length of copepods in the Sargasso Sea off Bermuda. J. mar. biol. Ass. U. K. 44: $589-600$

Durbin, E. G., Durbin, A. G. (1978). Length and weight relationships of Acartia clausi from Narragensett Bay, R. I. Limnol. Oceanogr. 23: 958-969

Frost, B. W. (1972). Effects of size and concentration of food particles on the feeding behaviour of the marine planktonic copepod Calanus pacificus. Limnol. Oceanogr. 17: 805-815

Frost, B. W. (1974). Feeding processes at lower trophic levels in pelagic communities. In: Miller, C. B. (ed.) The biology of the oceanic Pacific. Oregon State University Press, Corvallis, p. $59-77$

Gatten, R. R., Corner, E. D. S., Kilvington, C. C., Sargent, J. R. (1979). A seasonal survey of the lipids in Calanus helgolandicus (Claus) from the English Channel. In: Naylor, E., Hartnoll, R. G. (ed.) Cyclic phenomena in marine plants and animals. Pergamon Press, Oxford, p. 275-284

Harris, R. P., Paffenhöfer, G.-A. (1976). Feeding, growth and reproduction of the marine planktonic copepod Temora longicornis Muller. J. mar. biol. Ass. U. K. 56: 675-690

Ikeda, T. (1974). Nutritional ecology of marine zooplankton. Mem. Fac. Fish. Hokkaido Univ. 22: 1-97

Jaschnov, V. A. (1955). The morphology, distribution and systematics of Calanus finmarchicus s. 1. Zool. Zh. 34: $1210-1223$

Longhurst, A. R., Williams, R. (1976). Improved filtration systems for multiple serial plankton samples. Deep Sea Res. 23: $1067-1073$ 
Marshall, S. M. (1933). On the biology of Calanus finmarchicus. Il. Seasonal variations in the size of Calanus finmarchicus in the Clyde Sea area. J. mar. biol. Ass. U. K. 19: 111-138

Marshall, S. M., Nicholls, A. G., Orr, A. P. (1934). On the biology of Calanus finmarchicus. V. Seasonal distribution, size, weight and chemical composition in Loch Striven in 1933, and their relation to phytoplankton. J. mar. biol. Ass. U. K. 19: 793-818

Marshall, S. M., Orr, A. P. (1955). The biology of a marine copepod, Calanus finmarchicus (Gunnerus). Oliver and Boyd, Edingburgh

Matthews, J. B. L. (1967). Calanus finmarchicus s. l. in the North Atlantic. The relationships between Calanus finmarchicus s. str., C. glacialis and C. helgolandicus. Bull. mar. Ecol. 6: 159-179

McLaren, I. A. (1963). Effects of temperature on growth of zooplankton and the adaptive value of vertical migration. J. Fish. Res. Bd Can. 20: 685-727

Mullin, M. M., Brooks, E. R. (1970). The effect of concentration of food on body weight, cumulative ingestion, and rate of growth of the marine copepod Calanus helgolandicus. Limnol. Oceanogr. 15: 748-755

Nakai, Z. (1955). The chemical composition, volume, weight and size of the important marine plankton. Tokai Reg. Fish. Res. Lab., Spec. Publ. 5: 12-24

Omori, M. (1969). Weight and chemical composition of some important oceanic zooplankton in the North Pacific. Mar. Biol. 3: 4-10

Omori, M. (1970). Variations of length, weight, respiratory rate and chemical composition of Calanus cristatus in relation to its food and feeding. In: Steele, J. H. (ed.) Marine food chains. Edinburgh, Oliver and Boyd, Edinburgh, p. 113-126

Orr, A. P. (1934). On the biology of Calanus finmarchicus. IV Seasonal changes in weight and chemical composition of Calanus from Loch Fyne. J. mar biol. Ass. U. K. 20: 613-632

Paffenhöfer, G.-A. (1971). Grazing and ingestion rates of nauplif, copepodites and adults of the marine planktonic copepod Calanus helgolandicus. Mar. Biol. 11: 286-298

Paffenhöfer, G.-A. (1976). Feeding, growth and food conversion of the marine planktonic copepod Calanus helgolandicus. Limnol. Oceanogr. 21: 39-50

Razouls, S. (1977). Analyse pondérale, élémentaire et calorimétrique des stades juvéniles de copépodes pélagiques au cours d'une année. J. exp. mar. Biol. Ecol. 26: $265-273$

Rees, C. B. (1949). Continuous plankton records: The distribution of Calanus finmarchicus (Gunn.) and its two forms in the North Sea. Hull Bull. mar. Ecol. 2: 215-275

Vidal, J. (1980a). Physioecology of zooplankton. I. Effects of phytoplankton concentration, temperature, and body size on the growth rate of Calanus pacificus and Pseudocalanus sp. Mar. Biol. 56: 111-134

Vidal, J. (1980b). Physioecology of zooplankton. II. Effects of phytoplankton concentration temperature and body size on the development and moulting rates of Calanus pacificus and Pseudocalanus sp. Mar. Biol. 56: 135-146

Williams, R., Conway, D. V. P. (1982). Population growth and vertical distribution of Calanus helgolandicus in the Celtic Sea. Neth. J. Sea Res, 16: 185-194 